\title{
Increasing Procalcitonin Level of Blunt Thoracoabdominal Trauma Patients with ISS $\geq 16$ in Saiful Anwar General Hospital Malang
}

\author{
Sinung Wikanadi ${ }^{1}$, Thomas Erwin Huwae ${ }^{2}$. \\ ${ }^{I}$ General Surgery Resident, Medical Faculty Brawijaya University/Saiful Anwar General Hospital Malang. \\ ${ }^{2}$ Orthopaedic and Traumatology Consultant, Medical Faculty Brawijaya University/Saiful Anwar General \\ Hospital Malang. \\ *Corresponding author: Sinung Wikanadi
}

\begin{abstract}
:
Background: Trauma is the leading cause of death among productive age men and continue to be the cause of years of valuable life lost compared with cancer, heart disease, and stroke in combination. Thoracoabdominal trauma has great contribution to mortality of patient due to its anatomical position, contain vital body organs, the most body impact, and oftenly without any skin injury. Early prognosis evaluation of multitrauma patient is difficult. Clinical parameters which reflect patient's actual condition is required. Procalcitonin (PCT) has a very low level among healty individuals. PCT is known to be reliable biomarker in septic and infection cases dan has accuracy and clinical value to determine diagnosis of sepsis among critically ill patients. PCT as biomarker of SIRS in thoracoabdominal trauma and morbidity caused by SIRS has never been observed.

Materials and Methods: The prospective research was done in 4 months. Blood sampels were taken twice. First was taken within 24 hours after trauma. The latter was taken 72 hours after trauma. Inclusion and exclusion criterias were included. Confounding factors were also considered.

Results: 53 subjects were collected, 46 male and 7 female. 3 patients were dropped out because they died before the third day. Among 50 subjects, 25 subjects suffered from SIRS with 5 deaths, and 25 subjects were free from SIRS. Patients suffered from SIRS were included in statistical analysis.

The results were mean value of PCT level in the first day was 11.178 SD 11.568, which was significantly increased in the third day $13.998 \pm S D 14.496$ with $t$ value of -4.012 , with level of significancy 0.001. The mean PCT level of deceased patients from the first day was $25.98 \pm$ SD 13.47 which was significantly increased in the third day $25.98 \pm S D$ 16.74, with $t$ value of -4.119 , with level of significancy 0.05. Pearson correlation test towards increasing levef of PCT and SIRS revealed $r_{\text {counting }}$ was 0.708 with level of significancy 0.000, which means that, the more increasing level of PCT, the chance of SIRS event will also increasing.

Conclusion: PCT levels obtained during research reflect high level of inflammation over patients. The higher level of PCT level was associated with the amount of pro inflammatory cytokines relased by the body. This amount of cytokines revealed the extensive tissue damage resulted from trauma. The increasing level of PCT on the third day showed the extension of tissue damage resulted from trauma, which effected in the increasing release of pro inflammatory cytokines. It was concluded that blunt thoracoabdominal trauma patients suffered from SIRS, had increasing level of PCT.
\end{abstract}

Keywords: Blunt thoracoabdominal trauma, ISS $\geq 16$, SIRS, Procalcitonin.

\section{Introduction}

Trauma has become the leading cause of death for age productive men dan continues to be the cause of years of life lost compares to cancer, heart disease, and stroke combined. ${ }^{1}$ In Indonesia, trauma is the third leading cause of death after coronary heart disease and tuberculosis. ${ }^{2}$ Trauma compromise the patient's physiology and potentially cuase dysfunction of uninjured organs. ${ }^{3}$ Trauma alters the immune response of SIRS, induces organ dysfunction, and even leads to multiple organ failure. ${ }^{1,4}$

Thoracoabdominal trauma has great contribution to mortality of patients due to its anatomical position. ${ }^{5}$ Thoracoabdominal region,which most impact is, contains vital body organs, and oftenly without any visible skin injury. ${ }^{5}$ Blunt thoracic trauma oftenly shows no superficial injury, so does blunt abdominal trauma. But, these traumas transfer energy to the internal organs and may cause undetectable fatal effects and poor outcome. ${ }^{5}$ Thoracic trauma can cause potential threat to airway, breathing and circulation to the injured patient, that affect clinical outcome of the patient. ${ }^{6}$ Bleeding and infection are the potential threat of abdominal trauma. Abdominal trauma can be difficult to evaluate even in hospital setting. ${ }^{7}$

Early prognosis evaluation of multitrauma patient is difficult.Clinical parameters which reflect patient's actual condition is required. ${ }^{4}$ Previous clinical parameters for evaluating prognosis, such as urine 
production, oxygen saturation, blood gas analysis, C-reactive protein, base excess have limited function, since they emerged after organ disruption. ${ }^{4}$

Previous studies found that there were increasing level of procalcitonin in trauma patients. ${ }^{4,8,9,10}$ It had peak concentration after trauma on the first and third day. ${ }^{4}$ It is thought that procalcitonin can be used to observe inflammatory status on trauma patients. ${ }^{11}$ The role of procalcitonin in thoracoabdominal trauma has never been observed.

\section{Material And Methods}

This research was prospective. It has been done for four months. Subjects were patients suffered from thoracoabdominal trauma who were admitted. The inclusion criteria were thoracoabdominal trauma patients who were admitted within 24 hours after trauma, age within 18-60 years old, ISS $\geq 16$, never underwent operative procedure due to the trauma before admission. Whereas the exclusion criteria were having metabolic abnormality, BMI $\geq 25$. The confounding variables for the research were antibiotic and anti-inflammatory administrations, and performed operative procedure within 3 days sincetrauma.

Sampling technique for this research were consecutive. Blood samples were drawn twice. First, was within 24 hours after the trauma. Second, was 72 hours after the trauma. The statistical analysis used for the research was Product Noment Pearson correlation test.

\section{Results}

During the research, 53 subjects were collected. They were 46 male and 7 female. Three patients were dropped out becausethey died before the third day. Among 50 subjects, 25 subjects suffered from SIRS with 5 deaths, and 25 subjects were free from SIRS. Patients suffered from SIRS were included in statistical analysis. SIRS suffered deaths had high ISS score (over 40) and low PS score $(<60 \%)$. Patients suffered from SIRS were included in statistical analysis. Among 53 subjects, 3 subjects $(6 \%)$ had procalcitonin baseline level of $<2$ $\mathrm{ng} / \mathrm{dL}$, whereas 50 subjects $(94 \%)$ had procalciotonin baseline level of $>2 \mathrm{ng} / \mathrm{dL}$.

Table 1. Characteristics of subjects.

\begin{tabular}{|l|l|}
\hline Characteristic of subjets & \multicolumn{2}{|c|}{ Sex } \\
\hline Male & $4(87 \%)$ \\
\hline Female & $7(13 \%)$ \\
\hline \multicolumn{2}{|c|}{ Baseline level of procalcitonin } \\
\hline$<2 \mathrm{ng} / \mathrm{mL}$ & $3(6 \%)$ \\
\hline$>2 \mathrm{ng} / \mathrm{mL}$ & $50(94 \%)$ \\
\hline \multicolumn{2}{|c|}{ Event of SIRS } \\
\hline $\begin{array}{l}\text { SIRS } \\
\text { Uibfidfd }\end{array}$ & $25(50 \%)$ \\
\hline Survived & $20(80 \%)$ \\
\hline Deceased & $5(20 \%)$ \\
\hline No SIRS & $25(50 \%)$ \\
\hline
\end{tabular}

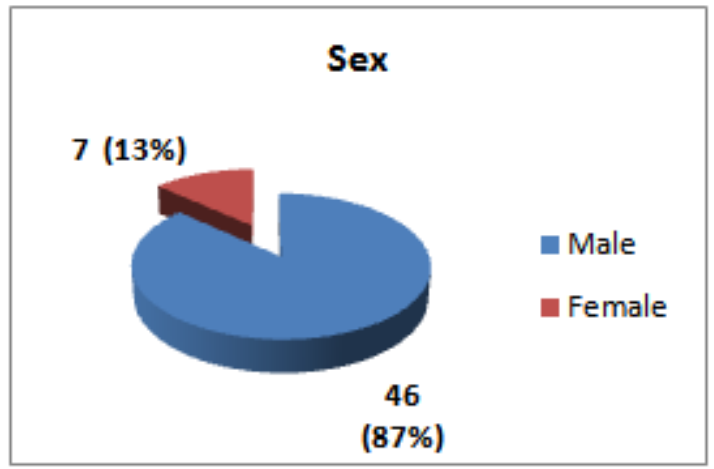

Picture 1. Characteristic of subjects (Sex) 


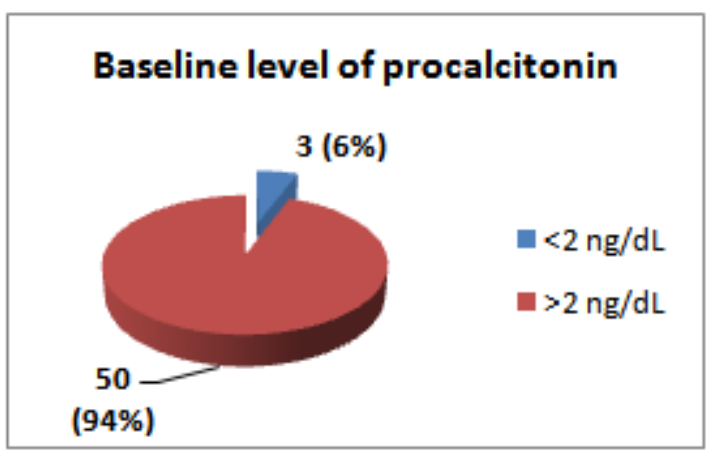

Picture 2. Characteristic of subjects (Baseline level of procalcitonin)

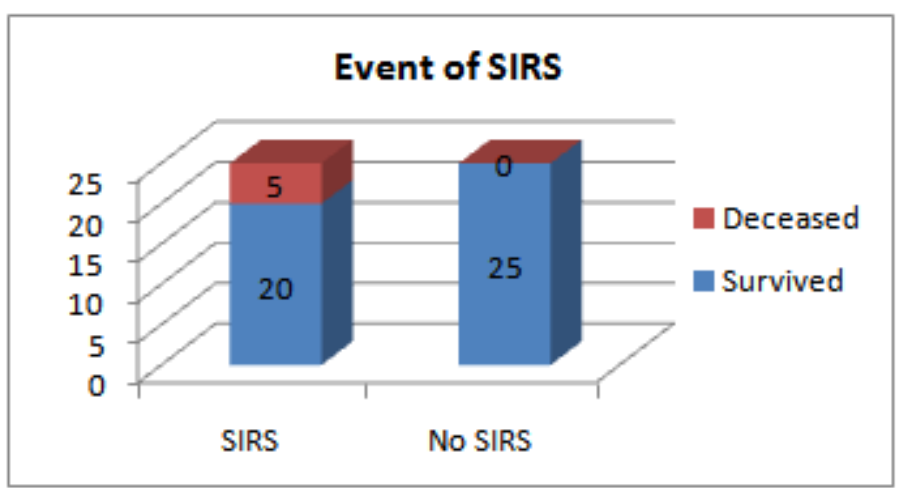

Picture 3. Characteristic of subjects (Event of SIRS).

The results were mean value of PCT level in the first day was 11.178 \pm SD 11.568, which was significantly increased in the third day $13.998 \pm$ SD 14.496 with t value of -4.012 , with level of significancy 0.001 (Table 2).

Table 2. Mean value of procalcitonin levels of patients with SIRS.

\begin{tabular}{|c|c|c|l|}
\hline Sample & Mean \pm DS & Paired T test & Significance \\
\hline Day one & $11.178 \pm 11.568$ & -4.012 & 0.001 \\
\hline Day three & $13.998 \pm 14.496$ & & \\
\hline
\end{tabular}

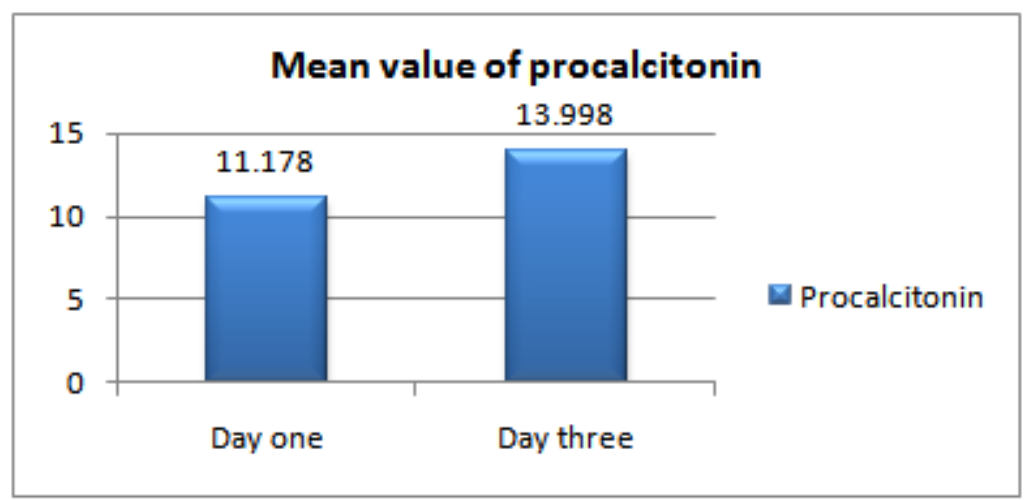

Picture 4. Mean value of procalcitonin level of patients with SIRS.

The mean PCT level of deceased patients from the first day was $25.98 \pm$ SD 13.47 which was significantly increased in the third day $25.98 \pm$ SD 16.74, with t value of -4.119 , with level of significancy 0.05 (Table 3).

Tabel 3. Procalcitonin level of deceased SIRS patients.

\begin{tabular}{|c|c|c|l|}
\hline Sample & Mean \pm DS & Paired T-test & Significance \\
\hline $\begin{array}{c}\text { Day one } \\
\text { 16 (8) } 10 \text { ) }\end{array}$ & $\begin{array}{c}25.98 \pm 13.47 \\
7(1207)\end{array}$ & -4.119 & 0.05 \\
\cline { 1 - 2 } Day three & $34.02 \pm 16.74$ & & \\
\hline
\end{tabular}


Deceased SIRS patients had significantly higher procalcitonin level compared to survived SIRS patients, as is shown in picture 5 .

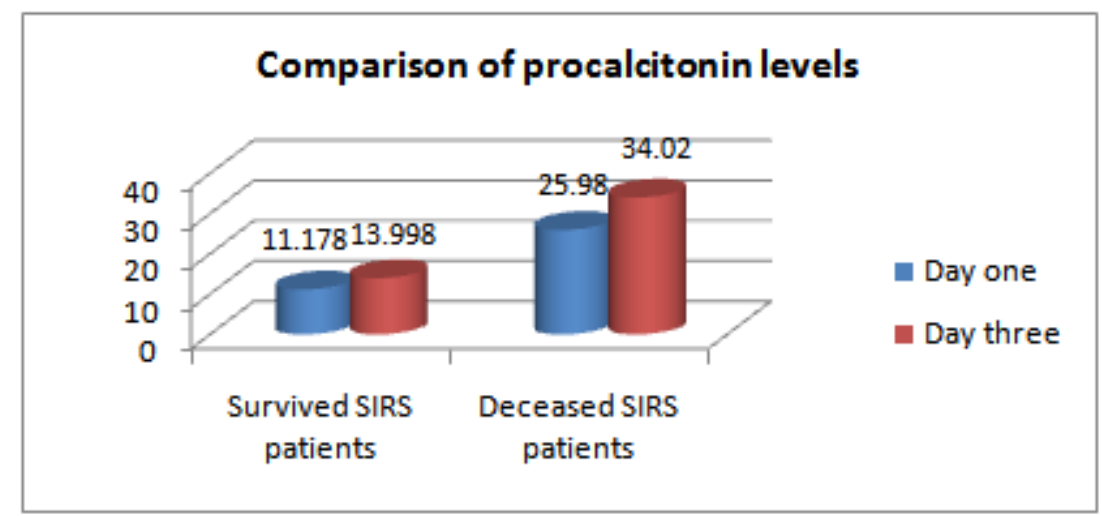

Picture 5. Chart showing comparison of procalcitonin levels in survived and deceased SIRS patients.

The result was, patients whose procalcitonin level increased on day three sample, would experience SIRS. Pearson correlation test was used to evaluatethe relation between increasing level of procalcitonin with SIRS. The test revealed $r_{\text {counting }}$ was 0.708 with level of significancy 0.000 , which means that, the more increasing level of PCT, the chance for SIRS will also increasing.

Table 4. Pearson Correlation test

\begin{tabular}{|c|c|c|c|}
\hline Variables & $\mathrm{R}_{\text {counting }}$ & Significancy & Information \\
\hline Procalcitonin difference & 0,708 & 0,000 & Significant relationship \\
\hline SIRS & & & \\
\hline
\end{tabular}

\section{Discussion}

This study resulted that patients who had increasing level of procalcitonin on the second sampling, would experienced SIRS. The increasing level of procalcitonin is suggested due to expanding tissue damage during trauma. Tissue damage promotes the release of inflammatory mediators. Inflammatory mediators such as TNF- $\alpha$, IL-1 $\beta$, IL-6 will resist endopeptidase. The function of endopeptidase is to alter procalcitonin to calcitonin. Since the function of endopeptidase is resisted, the proteolysis of procalcitonin is also resisted, resulted in increasing level of procalcitonin.

The amount of inflammatory mediators will correlate with the patient's inflammatory response. The increasing level of procacitonin from the first to second sample indicates the loads of proinflammatory mediators comparable with body's inflammatory response.

The increasing level of procalcitonin observed during this research is able to be used as early predictor of SIRS in thoracoabdominal trauma patients. Procalcitonin can also be used as an early predictor of morbidity. Procalcitonin monitoring is expected as marker for hyperinflamation in trauma patients, which is useful to consider definitive surgical procedure post trauma.

\section{Conclusion}

Trauma causes tissue damage which will then stimulates the release of inflammatory mediators. These inflammatory mediators will induce the the amount of procalcitonin through the inhibition of endopeptidase. Extensive tissue damage will cause large inflammatory mediators release, and further, procalcitonin existence. Hence, procalcitonin can be used as early predictor of SIRS in thoracoabdominal trauma patients.

\section{References}

[1]. Yagmur Y, Ozturk H, Unaldi M, Gedik E. 2005. Relation between Severity of Injury and the Early Activation of Interleukins in Multiple-Injured Patients. Eur Surg Res 2005,37:360-364. Diyarbakir, Turkey.

[2]. Badan Intelejen Negara. 2014. www.bin.go.id. Diakses 13 Juni 2014.

[3]. Butcher N, Balogh ZJ. 2009. The definition of polytrauma : the need for international consensus. Injury: International Journal of the care of the injured 40S4 : 12-22. Newcastle, New South Wales : Australia.

[4]. Giannoudis, Hildebrand, Pape. 2004. Inflammatory serum markers in patients with multiple trauma. The Jounal of Bone an Joint Surgery 2004;86-B:313-23. Leeds, UK.

[5]. Punia RK, Meena DV. 2013. Missed Injuries in Fatal Blunt Thoraco-Abdominal Region. J Indian Acad Forensic Med, JulySeptember 2013, Vol 35, No 3. 
[6]. Veysi VT, Nikolau VS, Paliobeis C, Efstathopoulos N, Giannoudis PV. 2009. Prevalance of chest trauma, associated injuries and mortality : a level I trauma center experience. Int Orthop. Oct 2009; 33(5): 1425-1433.

[7]. White M, Yancey AH. 2011. Abdominal Trauma. http://www.pearsonhighered.com/assets/hip/us. Diakses 3 Oktober 2014.

[8]. Wanner GA, Keel M, Steckholzer U, et al. 2000. Relationship between procalcitonin plasma levels and severity injury, sepsis, organ failure, and mortality in injured patients. Crit Care Med 2000;28:950-7.

[9]. Becker KL, Sneider R, Nylen ES. 2010. Procalcitonin in sepsis and systemic inflammation : a harmful biomarker and a therapeutic target. British Journal of Pharmacology (2010), 159, 253-264).

[10]. Wojtaszek, Marek et al. 2014. Changes of procalcitonin level in multiple trauma patients. Anaesthesiology Intensive Therapy 2014, vol 46, no 2, 78-82

[11]. Wanner GA, Keel M, Steckholzer U, et al. 2000. Relationship between procalcitonin plasma levels and severity injury, sepsis, organ failure, and mortality in injured patients. Crit Care Med 2000;28:950-7.

\footnotetext{
Sinung Wikanadi. "Increasing Procalcitonin Level of Blunt Thoracoabdominal Trauma Patients with ISS $\geq 16$ in Saiful Anwar General Hospital Malang." IOSR Journal of Dental and Medical Sciences (IOSR-JDMS) 16.7 (2017): 67-71.
} 